\title{
Aproximación a la filosofía de la religión de Xavier Zubiri
}

¿Cómo sc silúa la filosofía de la religión de Xavier Zubiri en el marco de los saberes filosóficos y leológicos sobre la religión? ¿En qué consiste su originalidad? Un estudio sistemático de la filosofía zubiriana de la religión tendría que abordar críticamente temas. como la religación, la idea de Dios, la experiencia religiosa, la historia de las religiones o la posición del cristianismo'. Pero, tal vez, antes de un estudio sistemático de esa índole, sea útil llamar la atención sobre la originalidad del planteamiento de Zubiri respecto a otros enfoques habituales de la filosofía de la religión. Los grandes temas de la filosofía de la religión han sido abordados por la fenomenología religiosa, la filosofía analítica, la crítica explicativa de la religión y la teología natural clásica. Un estudio sistemático de la filosofía de la religión de Zubiri podría ser favorecido precisamente por un estudio preliminar en el que se sitúe el pensamiento religioso de Zubiri en el contexto de esos saberes, clásicos y modernos, sobre la religión.

Ante todo. conviene señalar que, si el estudio zubiriano de la religión tiene una novedad cualitativa frente a otros estudios del hecho religioso, ello se debe precisamente a la originalidad de su método filosófico. Obviamente, la novedad de su método hay que buscarla, en último término, en la novedad de su filosofía de la inteligencia contenida en sus tres tomos sobre la Inteligencia sentiente? Zubiri se interna en el estudio de la religión con un método filosófico que se distingue decisivamente del mélodo fenomenoiógico-hermenéutico, del método del análisis lingüístico y de los métodos crítico-explicativos al uso. Sin embargo, esta originalidad del método zubiriano no implica una ceguera ni una cerrazón respecto a los resultados de otras aproximaciones al hecho religioso. Al contrario, el método de Zubiri, por su carácter enormemente comprehensivo e integrador, puede integrar en su seno los resultados de otros métodos. Justamente por ello Zubiri puede proporcionarnos una magnffica visión sintética de la experiencia religiosa de la humanidad, contenida en sus tres tomos dedicados al estudio del Problema teologal del hombre"'. 


\section{La fenomenología de la religión}

La filosolía de Zubiri se gestó a partir de la formación fenomenológica del joven fïlósofo. Por eso mismo, las diferencias entre el pensamiento religioso de Zubiri y la fenomenología de la religión representan un buen punto de partida para entender la originalidad del método zubiriano.

Zubiri calilica su esludio de la religación como un "análisis de hechos" . Esto distingue al método zubiriano del método fenomenológico en una cuestión decisiva. El método fenomenológico pretende comprender el sentido de las vivencias religiosas. antes de decidir fïlosóficamente sobre su verdad o falsedad. Esta comprensión toma en la actualidad frecuentemente un carácter hermenéutico, integrando así el redescubrimiento de la tradición en autores como P. Ricoeur o H.-G. Gadamer". Antes de explicar los contenidos de una vivencia es necesario comprender su sentido. Es la famosa diferencia entre "comprensión" y "explicación" " El método de Zubiri prelende situarse en un ámbito más radical que toda comprensión y a fortiori que toda explicación. Es el análisis de los hechos que después serán comprendidos y explicados. En concreto, el hecho que Zubiri analiza es el hecho de la religación en cuanto apoderamiento por el poder de lo real'. Y el poder de lo real es algo que está dado en toda aprehensión de realidad, con independencia del sentido concreto que pueda tener cada una de las cosas aprehendidas ${ }^{x}$. La religación. así entendida, es anterior a todo sentido explícitamente religioso, tales como los que estudia la fenomenología de la religión. Antes de que ciertas cosas tengan el sentido de ser algo "sagrado", "numinoso", "fascinante", "misterioso" o "tremendo"", toda la realidad tiene de hecho una poderosidad que me religa. En cuanto análisis de hechos, el método de Zubiri apunta a un ámbito que la lenomenología de la religión, en virtud de su propio método comprensivo, ha ignorado hasta el presente.

Esıo le posibilita a Zubiri la elaboración de una definición universal de la religión, frente a las dilicultades que una definición de este tipo presenta a la fenomenología"'. No todas las religiones han dispuesto de un concepto de lo religioso, pues nunca se han tenido que definir a sí mismas frente a otros ámbitos culturales no religiosos. Esto ha sucedido en la cultura occidental, aunque no significa que su concepción sobre lo religioso se pueda imponer a otras culturas. En este punto, la fenomenología de la religión tiene que proceder de un modo semejante al método de las "variaciones" de Husserl, buscando no imponer a todas las religiones los sentidos particulares que se vivencian una de ellas. El resultado puede ser una definición de lo religioso en función de sentidos enormemente generales y, por tanto, también vacíos. Incluso, cuando se utilizan algunos sentidos aparentemente universales como "lo sagrado", algunos podrían objetar que no todas las religiones se entienden a sí mismas en función de la sacralidad, sino que afirman más bien una ruptura de toda distinción entre lo sagrado y lo profano. Respecto a estos problemas, Zubiri puede llamar la aten- 
ción sobre la religación como un hecho universal, anterior a todo sentido religioso. Y, precisamente por ello. puede aceptar toda la multiplicidad de sentidos religiosos como plasmaciones concretas de la religación en diferentes religiones" . De este modo, los diferentes sentidos religiosos que aparecen en las diversas religiones no quedan nivelados por un sentido general, sino referidos a un hecho más radical que todo sentido. La religación, como hecho radical, permitiría incluso conceptuar cierlas plasmaciones "seculares" de la misma que no encajan en ninguno de los sentidos "religiosos" habitualmente utilizados". La plasmación de la religión desborda el marco de los cuerpos religiosos históricamente constituidos.

Otra ventaja del planteamiento consiste en una cierta neutralidad hermenéutica. El análisis de hechos no requiere una sensibilidad especial del analista para el fenómeno religioso. En cambio. la fenomenología de la religión ha reclamado la necesidad de una sensibilidad especial del estudioso ${ }^{13}$. La idea tiene un fundamento hermenéutico: es obvio que no lodas las personas dan un sentido religioso a sus experiencias cotidianas. $Y$ la hermenéutica señala que no es posible entender el sentido de una vivencia pasada sin alguna pertenencia (Zugehörigkeit) a la tradición en la que esa vivencia se formula ${ }^{14}$. Todo esto es perfectamente cierto desde el punto de vista del sentido. Solamente si hay una comunidad en el "campo" u horizonte de sentido es posible entender los sentidos religiosos de las vivencias de los demás ${ }^{15}$. Pero Zubiri se ha situado, en su análisis de la religión, en un ámbito más radical que el del sentido. La religación no es un sentido sino una dimensión accesible a un análisis de la realidad, tal como ésta se actualiza en aprehensión primordial. Zubiri no negaría la necesidad de una afinidad entre el investigador y la vivencia religiosa investigada. Pero señalaría que el hecho de la religación, por no consistir en una vivencia de sentido, se sitúa en un ámbito accesible para todo estudioso, con independencia de su sensibilidad religiosa particular.

Ahora bien, Zubiri podría asumir perfectamente todos los resultados del método fenomenológico-hermenéutico entendido como análisis del logos religioso (de los distintos lógoi religiosos), ulterior al análisis de la religación. El análisis puede versar no sólo sobre la poderosidad de la realidad, sino también sobre el logos religioso en que la religación se ha plasmado en las distintas religiones. Como la fenomenología, estaríamos todavía en un plano anterior a toda explicación teórica de la religión tratando solamente de describirla. Además, el análisis de hechos de Zubiri comparte con la fenomenologfa el respeto por la originalidad de lo religioso. La religación y los sentidos religiosos en los que ésla se plasma no se tratan de reducir apresuradamente a procesos sociológicos o psicológicos, sino que comienzan siendo analizados en su facticidad primordial. Por eso, el método de Zubiri puede ser buen aliado de las ciencias de las religiones, tales como la historia de las religiones, la sociología religiosa o la psicología de la religión. Zubiri puede proporcionarles a estas ciencias un concepto de lo 
religioso que es anterior a toda decisión teórica sobre su verdad o falsedad. En la medida en que su definición de lo religioso sea preferible a la fenomenológica, su utilidad para la ciencia de las religiones sería superior. El mismo Zubiri trata de mostrar esto haciendo una relectura del Traité d'histoire des religions, de $\mathbf{M}$. Eliade, desde el punto de vista del poder de lo real'th.

\section{La filosofía analítica de la religión}

Sobre la relación entre el mélodo de Zubiri con la filosolía analítica de la religión, puede decirse algo semejante a lo ya dicho sobre la relación con el mélodo fenomenológico. Zubiri puede señalar que la religión no es primariamente cuestión de significado, sino que su raíz se sitúa en un ámbito más radical que es el de la religación. De nuevo esto no significa que no sea legítimo y necesario el análisis del lenguaje religioso. Sin embargo, la perspectiva propia de Zubiri puede aportar algunas novedades importantes a la filosofía analítica de la religión.

Zubiri afirma que el hecho de la religación constituye un ámbito estructuralmente anterior al lenguaje religioso. $Y$, precisamente por ello, desde la filosofía de Zubiri se podría situar en una perspectiva nueva el problema del referente de los enunciados religiosos. En la filosolía analítica de la religión se ha llamado la atención repetidamente sobre la dificultad de asignar significado a proposiciones que, por su misma indole religiosa, no son verificables. Esto se debería a la inexistencia de hechos positivos que pudieran refutar las pretensiones de verdad de los enunciados religiosos. Los objetos de los que tratan las proposiciones religiosas escaparían a toda verificación positiva, y justamente por ello las proposiciones religiosas carecerían de significado ${ }^{17}$. Ahora bien, la religación, para Zubiri, no es sólo un hecho sino un hecho positivo. Si llamamos hecho a todo lo actualizado en la aprehensión, los hechos específicamente positivos serían aqueIlos hechos que por su propia índole serían aprehensibles por cualquiera' ${ }^{1 \mathrm{~g}}$. La religación, precisamente por ser un momento de toda aprehensión de lo real, serfa un hecho positivo. De este modo, el hecho de la religación proporcionarfa un ámbito primario en el que atribuir significatividad a los enunciados religiosos. Naturalmente, esto exige que el significado no se entienda en términos de representación, tal como pensaba el neopositivismo, sino como "direccionalidad"' . Los enunciados religiosos no serían simples expresiones emocionales, carentes de significado, sino que su significación consistirfa primariamente en un intento de dar sentido al hecho de la religación $n^{20}$.

Es importante señalar que el modo en que Zubiri entiende este hecho le permite recoger algunas de las aportaciones de aquella filosofía analítica de la religión que se deriva del segundo Wittgenstein. Cuando Zubiri estudia el planteamiento del problema de Dios que aparece en las Ilamadas vias antropologicas, sen̄ala que éstas no han partido de hechos, sino de momentos de ese hecho. Ello 
se debe, según Zubiri, a que se ha partido de la intelección (Agustín), del sentimiento (Schleiermacher) o de la volición (Kant) aisladamente considerados. En cambio, para Zubiri, la intelección, el sentimiento y la volición poseen una radical unidad. Solamente en la unidad de los tres podrfa hablarse de un hecho plenamente ||$^{21}$. Pues bien, conviene no olvidar que este hecho que engloba intelección, sentimiento y volición no es otro que la acción ${ }^{22}$. Esto confluiŕa con la idea del segundo Wittgenstein según la cual el significado de las proposiciones religiosas, corno de cualquier otra proposición, no se puede considerar al margen de la praxis en la que éstas surgen ${ }^{23}$. Lo propio de Zubiri estaría en llamar la atención sobre la necesidad de analizar, antes que esos significados religiosos, la religación como hecho que aparece en nuestras acciones.

Con esto no se evade el problema de la verificación de los enunciados religiosos, pero se lo sitúa en su lugar propio. La filosofía analítica de la religión se ha dedicado preferentemente a los enunciados propios del teŕsmo, planteándose explícitamente la dificultad de verificar las proposiciones referidas a "Dios". La famosa "parábola del jardinero" pone de relieve estas dificultades: ¿en qué se diferencia un jardinero invisible, inaudible, inodoro intangible, etc., de un jardinero imaginario $o$, simplemente, de un jardinero inexistente? $?^{24}$ La filosoffa de Zubiri puede llamar la atención sobre la diferencia entre proposiciones referidas a lo actualizado en nuestra aprehensión y las proposiciones referidas a alguien que, por definición, transciende todo acto (que serían las propias del monoteŕsmo). Pero no toda proposición religiosa está en esta situación: los sentidos religiosos que estudia la fenomenología de la religión se refieren frecuentemente a realidades actualizadas en nuestra aprehensión: es la sacralidad de los ríos, de las piedras, de los astros, etc. El problema de la verificación se limilaría a proposiciones religiosas que pretenden transcender lo actualizado en nuestra aprehensión, como es el caso de las proposiciones referidas a "Dios". Y esto nos conduce al tema de la explicación de los hechos religiosos.

\section{Los métodos crítico-explicativos}

La perspectiva de Zubiri puede integrar, además del análisis del hecho religioso, las distintas teorías explicativas sobre el mismo. Entendemos por tales aquellos intentos de buscar un fundamento al hecho religioso más allá de nuestra aprehensión. Así, por ejemplo, el hecho religioso se puede explicar a partir de la necesidad de compensar las injusticias sociales (Marx), o en virtud de una "neurosis obsesiva de la humanidad" (Freud) ${ }^{29}$. Estas teorías explicativas son generalmente teorías críticas de la religión en el sentido que le niegan al hecho religioso su pretendida autonomía y lo derivan de otros ámbitos de la realidad, como puede ser la realidad social o los procesos psicológicos. Sin embargo, esto no significa, como piensan algunos representantes de los métodos fenomenológicohermenéuticos, que la explicación de la religión consista necesariamente en una reducción ilegítima de ella a instancias de que le son totalmente ajenas. Desde la 
perspectiva de Zubiri, es una tarea perfectamente legitima de la razón el intento de explicar lo que hay actualizado en nuestro campo de realidad a partir de otras instancias que lo transcienden. Si el uso del mélodo explicativo fuera prohibido de la filosofía de las religiones, no sólo serĺa ilegítimo fundamentar los hechos religiosos en determinados factores sociológicos o psicológicos, sino también en la realidad de Dios.

Con todo, la filosolía de Zubiri puede proporcionar algo de clarificación en este punto. Zubiri ha subrayado que todas las formas de intelección se mueven en la apertura constitutiva de la formalidad de realidad. De ahí que, cuando la razón encuentra un fundamento para los objetos que quiere explicar, nunca pueda estar segura de que el fundamento encontrado es el único fundamento posi$b^{2 \hbar}{ }^{2 \hbar}$. Precisamente por ello. una explicación psicológica de la religión no liene que ser necesariamente incompatible con una explicación sociológica de la misma. Pero, del mismo modo, ni las explicaciones psicológicas ni las explicaciones sociológicas son por principio excluyentes de una explicación de la religión a partir de una realidad-fundamento, a la que usualmente llamamos Dios. Demostrar que el fundamento esbozado explica el objeto en cuestion, no equivale en modo alguno a demosirar que ese fundamento es el único posible. De ahí que una metafísica que pretenda una solución teísta al problema de la religación no tenga ninguna razón para temer cualquier explicación sociológica o psicológica de la religión. Solamente ha de mostrar la falsedad de la pretendida exclusividad de esas explicaciones.

Es posible que las explicaciones de la religión puedan ser de algún modo verificadas en términos sociológicos o psicológicos. No es algo tan obvio, y la lectura actual de explicaciones de la religión como la de Freud no dejan de producir una fuerte impresión especulativa. Sin embargo, aquí nos interesa la posibilidad de verificar explicaciones religiosas tales como las que propone el monoteísmo. Respecto a este problema. no cabe duda de que Zubiri nos proporciona un concepto suficientemente abierto de experiencia. Las parábolas de Oxford normalmente presuponen una idea de experiencia como pura empiria. A diferencia de tales presupuestos, Zubiri dispone de un concepto más comprehensivo de experiencia. Para él, la experiencia tiene un carácter marcadamente racional: la razón crea esbozos sobre lo que las cosas sean en su fundamento allende nuestra aprehensión, y la realidad en la aprehensión es ahora inleligida a luz del fundamento esbozado. La experiencia. en este sentido, no siempre incluye la aprehensión sensible de lo esbozado. Incluso en ese tipo especialmente controlado de experiencia que es el experimento científico, lo esbozado no siempre es aprehendido sensiblemente: muchos experimentos se limitan a controlar las consecuencias que lo esbozado tendría que tener en el plano de la aprehensión"7.

¿Se puede decir algo semejante de la experiencia religiosa? En muchos casos, las discusiones fílosóficas sobre la experiencia religiosa toman como punto 
de partida la religión cristiana, y se preguntan directamente por su verificación. Pensemos, por ejemplo. en la parábola de la ciudad celeste: mientras que un caminante espera que al linal del camino se enconirará con una ciudad celeste, el otro caminante sostiene que tras la última curva no encontraremos nada ${ }^{2 \mathrm{k}}$. La parábola quería subrayar frente a Flew la posibilidad de una verificación de ultratumba. Pero, naturalmente, este tipo de verificaciones se refieren a religiones que cuentan con algún tipo de supervivencia a la muerte. El judaísmo, por ejemplo, no pensaba así hasta épocas relativamente recientes y. por tanto, exigía a Yahweh una verificación histórica.

¿Tiene sentido esperar algún tipo de verificación histórica de las religiones? En ocasiones, los filósolos trabajan con una idea de la divinidad tan depurada, que tiende a ocultar el hecho de que la mayor parte de las religiones, incluso en la actualidad, cuentan con algún tipo de verificación histórica de la divinidad. El teólogo Pannenberg ha llamado la alención sobre este hecho: los dioses que aparecen en la historia de las religiones han de mostrar su verdad en la historia humana. Y en esa historia se van verificando o van siendo abandonados. Así, por ejemplo, los dioses guerreros. encargados de la prosperidad de un imperio, sobreviven en la medida en que el imperio sobrevive, y fenecen cuando no son capaces de proteger a los suyos. Es, por ejemplo, lo que sucedió con los dioses aztecas, en la interpretación de los propios sabios nahuas, según los famosos diálogos de Tlatelolco. Ahora bien, ciertos dioses no agotan sus funciones en la detensa de un determinado pueblo, o muestran la posibilidad de encajar mejor los descalabros de la historia. Estos dioses van sobreviviendo, pues se muestran más capaces de dar cuenta de la historia en su complejidad, llegando incluso a aparecer dioses que quieren explicar la historia en su totalidad. Sería el proceso experimentado por el Yahweh a lo largo de la historia de Israel, culminando en el cristianismo. La religión verdadera sería aquella que pudiera dar cuenta de la tolalidad en su unidad y su historicidad ${ }^{23}$.

Sin embargo, la verificación, en la perspectiva de Zubiri, no puede consistir primariamente en la capacidad que pueda tener una religión para explicar la realidad en su totalidad y su unidad. Y es que, para Zubiri, la religión no es primariamente una cosmovisión, sino una plasmación de la religación. Por tanto, el lundamento religioso no se verilica primariamente en su capacidad para dar cuenta de la totalidad. sino en su capacidad de fundamentar el hecho de la religación del que hemos partido. Ello no excluye, por supuesto, que el lundamento último sea también lundamento de la realidad en cuanto tal. Pero esta realidad no es para Zubiri una tolalidad hegeliana, sino una lormalidad constitutivamente abierta. De ahi la imposibilidad de pensar la verdad racional como un ajustamiento entre la totalidad y nucstros conceptos. Para Zubiri, Dios no sería experimentado primariamente como verdad acerca de la totalidad, sino como fundamento de la religación a la hora de hacer la propia vida ligado a ese 
fundamento. Se trata, por tanto, de una experiencia concreta y no de una teoría acerca de la tortalidad.

Pero, ¿se puede de algún modo tener la experiencia concreta de ese fundamento de la propia religación? Pareciera que la historia misma de las religiones va haciendo desaparecer la vinculación del fundamento con experiencias concretas (Iluvia, cosechas, guerras, etc.), y alejándolo hacia una lejanía inmanipulable. ¿Es el destino de Dios convertirse entonces en un deus otiosus, no manipulable, pero tampoco experimentable en un mundo secularizado? La respuesta para Zubiri es que, si bien no podemos tener experiencia de Dios, sí podemos ser experiencia de Dios, viviendo nuestra vida ligados a Aquél que hemos postulado como el fundamento último del poder de lo real. Sería un planteamiento que enlazaría con algunas ideas del último Bonhoeffer: vivir y morir como si Dios no existiera, pero viviendo y muriendo entonces justamente como Dios quiso vivir y morir entre nosotros ${ }^{30}$. Ahora bien, ¿es esto realmente una verificación? ¿Es ésta una experiencia de Dios o solamente una experiencia de nuestra fe en Dios? Zubiri insistirfa en que se trata de una experiencia de Dios mismo: a Dios no se le postula solamente como lo más otro de nosotros mismos, sino también como el más cercano (alienum valde pero intimior intimo meo). Para Zubiri, Dios no es transcendente "a" las cosas, sino transcendente "en" ellas". Haciendo nuestra vida fundamentados en Dios, comprendemos nuestra propia realidad como una experiencia del Dios en el que vivimos, nos movemos y somos ${ }^{32}$.

\section{La teología natural}

En ambiente católico se suele presuponer que los discursos filosóficos sobre Dios, cuando culminan en el teísmo, son útiles para la teología. El concilio Vaticano I consagró este modo de pensar y decretó la posibilidad de un conocimiento natural de Dios con independencia de la fe. En la teología protestante, en cambio, es más frecuente decretar la heterogeneidad entre las pruebas filosoficas de Dios y el Dios revelado en Jesucristo. En este siglo. Karl Barth ha sido quien ha llamado la atención sobre la diferencia entre la religión (intento humano de Ilegar a Dios) y la fe (acogida humana del Dios que libremente se revela). Para Barth existe en la escolástica católica un intento de poner al mismo nivel, como simples escalones de una misma escalera, hombre y Dios, naturaleza y gracia, razón y fe, filosofía y reologia, reduciendo a conceptos manejables la tolal alteridad de Dios, totaliter aliter. De ahí también la tendencia a nivelar la Escritura y la tradición, a Jesús y a Marla, a Cristo y al papa. Tanto el hombre como Dios caerían bajo un mismo concepto de ser, el cual, pese a todas las diferencias que se quieran subrayar, se aplicaría alegremente a ambos. La analogia entis sería "la" invención del Anticristo, cuya expresión práclica sería el culto a María". En una línea más reciente, Eberhard Jüngel ha renovado la crítica a la analogía del ser, si bien en una dirección distinta a la de Barth. Para Jüngel, la razón es verdaderamente racional cuando reconoce que a un Dios que sea Dios solamente 
se le puede conocer si él mismo se revela. Y la idea helénica de Dios como ser pleno ha impedido entender a Dios allí donde él se ha querido revelar: en la negatividad de la cruz: ${ }^{14}$.

Cabría pensar si estas críticas protestantes a la teología natural se pueden aplicar también al intento de Zubiri. Una impresión superficial podría hacer pensar que sí. En Zubiri encontramos un esquema que puede recordar al de la escolástica tradicional: primero viene una mostración de la realidad de Dios y, uras un recorrido por la historia de las religiones, se culmina en una indagación sobre las características propias del Dios cristiano. Tendríamos una continuidad entre filosofía y teología, entre razón y fe, entre naturaleza y gracia, sin especiales rupturas entre ambas. Dios sería una realidad accesible al esfuerzo religioso del hombre, y la revelación sería una simple interpretación teológica de ese esfuerzo humano. El fundamento absolutamente absoluto sería accedido en esa búsqueda religiosa, de la cual el cristianismo no sería sino un estadio más avanzado. También en Zubiri encontraríamos algo así como una analogia entis, pues tanto el hombre como Dios serían realidades, una absolutamente absoluta y otra relativamente absoluta, pero situadas en el mismo plano de la realidad. En El hombre y Dios tendríarnos lo que Barth Ilamaba "el maldito ' $y$ ' católico", donde se acaba convirtiendo a Dios en un artefacto metafísico.

En descargo de Zubiri se podrían señalar algunas diferencias de su planteamiento con la teología natural clásica. Una primera diferencia es la clara conciencia de Zubiri sobre la insuficiencia de los conceptos helénicos a la hora de pensar el Dios de la religión cristiana. Zubiri nos dice que el Dios de las religiones es el mismo Dios de la filosofía cuando ésta no se acantona en nociones griegas $^{35}$. Esta liberación de los conceptos helénicos tiene consecuencias inmediatas a la hora de pensar a Dios. Zubiri rechaza aplicarle el concepto de ser a Dios, conectando de este modo con importantes corrientes del neoplatonismo y de la teología negativa. Con todo, es cierto que tanto el hombre como Dios siguen siendo pensados en términos de realidad, de modo que no nos habriamos liberado del problema planteado por Barth. Dios dejaría de ser el totalmente otro para convertirse en una proyección magnificadora del ser humano, perfectamente dominable por éste. Sin embargo, aquif hay que tener en cuenta, en primer lugar, que lo que Zubiri llama realidad no es "el concepto más universal" sino una formalidad constitutivamente abierta, en la que no cabe ningún cierre conceptual que la domine. Y, por otra parte, la realidad es para Zubiri alteridad, y no una alteridad simplemente referida a un sujeto (como en las filosofias de la alteridad), sino una alteridad que no refiere a nada más que a si misma ("de suyo"). Por tanto, la afirmación de Dios como realidad absolutamente absoluta es perfectamente compatible con la afímación barthiana de su total alteridad (por más que esa realidad sea, por otra parte, la que me constituye personalmente). 
Esto se muestra en el tratamiento que Zubiri le da al problema de la analogía. La analogía no aparece en Zubiri como una vía de ascenso desde el mundo hacia Dios, sino como una vía descendente a partir de la realidad absolutamente absoluta de Dios. Es lo que Zubiri llama "analogía del absoluto", la cual podría ser de algún modo compatible con lo que Barth en su segunda época llama "analogía de la le", en el sentido de resaltar la humanidad de Dios ${ }^{*}$. También podría ser compatible con el planteamiento de Jüngel sobre "el Evangelio como discurso análogo sobre Dios". Es una analogía descendente pero más radical que la analogia entis, porque no subraya "una mayor diferencia cuanto mayor es la identidad" "17, sino "una mayor identidad cuanto mayor la diferencia", que es precisamente lo que sucede en la cncarnación ${ }^{\text {?k }}$. Partiendo de Dios como realidad absolutamente absoluta, Zubiri puede señalar que una realidad tal tendrá, por ser absolutamente absoluta. unidad, personeidad $e$ inteligencia. $Y$ añade "que estos caracteres se encuentren también de alguna manera en el hombre, no puede negarse. Pero, observemos, primero, que no hemos llegado a ellos a través del hombre sino de lo que es la realidad absolutarnente absoluta. Y. segundo, que si el hombre los posee es precisamente porque su ser es relativamente absoluto, esto es, porque Dios los posee de un modo absolutamente absoluto" ${ }^{39}$. La analogía, en el pensamiento de Zubiri, no es el modo como los hombres pueden conquistar la divinidad, sino más bien el modo en que la divinidad llega a los hombres.

Que esto pueda ser dicho lïlosóficarnente, al margen de la revelación, es lo que diferencia a Zubiri de posiciones como las de Barth o Jüngel. Pero una primacía de la revelación como la que afirman Barth o Jüngel no debe conducir necesariamente a rechazar globalmente el planteamiento de Zubiri. La filosofía de Zubiri puede servir precisamente para depurar muchos presupuestos filosoficos que siguen estando presentes en la teología de Barth y de Jüngel, a pesar de todas sus posiciones polémicas lienle a la filosofía. Así, por ejemplo, Barth sigue manteniendo una concepción tnarcadamente hegeliana de la divinidad, según un modelo decididamente subjetual. El sujelo absoluto de Hegel es, en Barth, el punto de partida para pensar la Trinidad ${ }^{41}$. Del mismo modo, Jüngel sigue pensado realidades positivas, como el dolor, el sufrimiento y la muerte con el concepto griego de negatividad. La identificación de Dios con Cristo sería, para Jüngel, una asunción de la negatividad en el seno mismo de la divinidad. Desde la perspectiva de Zubiri, las cosas pueden ser consideradas de otro modo. La encarnación no une a Dios con la nada, sino con las realidades positivas de la historia humana, por mucho que esas realidades puedan ser calificadas como "negativas" desde un punto de vista élico. Pero el mal no es una pura nada, sino una condición real de las cosas" con la cual se enfrenta Cristo en la cruz. Precisamente por ello el significado de la cruz no se puede reducir a sus implicaciones existenciales, como tiende a pensar Jüngel ${ }^{42}$, sino que implica una solidaridad de Dios con una historia real donde hay dolor, sufrimiento y muerte. Desde este punto de vista, la filosofía no significa necesariamente un impedi- 
mento para la teología, sino también un instrumento para superar presupuestos filosóficos inconscientemente admitidos por la teología.

\section{Conclusión}

Todo esto nos sitúa ya en el ámbito de la teología cristiana. No era el objetivo de estas líneas. Nuestra pretensión se limitaba a mostrar la originalidad de la posición de Zubiri en el marco general de los distintos saberes filosóficos sobre la religión. Zubiri no ha elaborado una fenomenología de la religión, una filosofía analítica de la religión, ni una teoría crítico-explicativa de la religión. Su planteamiento se sitúa en un ámbito nuevo determinado por su trilogía sobre la Inteligencia sentiente. Desde las posibilidades abiertas por esta obra, Zubiri puede proporcionar una nueva tilosofía de la religión, anclada en su análisis de la inteligencia sentiente. Esta filosofía de la religión es capaz de integrar en sí misma los resultados no sólo de las ciencias de las religiones, sino también de otras aproximaciones filosóficas al hecho religioso. Tanto el análisis de las vivencias religiosas como el análisis del lenguaje religioso pueden ser asumidos, desde una perspectiva zubiriana, en un análisis del logos religioso. Las teorías crítico-explicativas de la religión pueden ser integradas en un análisis zubiriano de la razón religiosa. Sin embargo, todos estos logros de otras disciplinas son remitidos, en la perspectiva de Zubiri, al análisis primario de la religación. A partir de este ańlisis, Zubiri puede considerar el logos religioso y la razón religiosa no sólo abstractamente, sino sobre todo desplegándose en la historia de las religiones y culminando en el cristianismo. Desde el punto de vista de Zubiri, "la historia de las religiones no es catálogo o museo de formas coexistentes y sucesivas de religión", sino "la experiencia teologal de la humanidad, tanto individual como social e histórica, acerca de la verdad última del poder de lo real, de Dios"4?.

San Salvador, julio de 1998.

\section{Notas}

1. Sobre la filosofía de la religión de Zubiri puede verse Gracia, D.. "Religación y religión en Zubiri", en Fraij6. M. (ed.), Filosofía de la religión, Madrid, 1994, pp. 491-512; Pintor-Ramos, A.. "Religación y prueba de Dios en Zubiri". Razón y fe 218, 1988, pp. 319-336.

2. Cf. Zubiri. X., Inteligencia sentiente. Inteligencia y realidad, Madrid, 1981; Inteligencia y logos, Madrid, 1982; Inteligencia y razón, Madrid. 1983.

3. Cf. Zubiri, X.. El hombre y Dios. Madrid. 1984; El problema filosofico de la historia de las religiones, Madrid. 1993: El problema teologal del hombre: cristianismo, Madrid, 1997.

4. Cf. Zubiri, X., El hombre y Dios, op. cit., pp. 93 y 371. 
5. Esto no quiere decir que la fenomenología de la religión se limite a una aplicación de los métodos filosóficos de la fenomenología husserliana o de la hermenéutica filosófica. Sobre este asunto puede verse Velasco. J. M., "La fenomenología de la religión en el campo de los saberes sobre el hecho religioso. Status quaestionis", en Gómez Caffarena. J. y Mardones. J. M. (eds.). Cuestiones epistemológicas. Materiales para una filosofia de la religión, vol. I. Barcelona, 1992, pp. 13-58.

6. Cf. Fierro. A., "Comprensión y explicación del hecho religioso", en Gómez Caffarena, J. y Mardones, J. M.. Cliestiones epistemológicas. Materiales para una filosofía de la religión, vol. I, op. cil., pp. 59-84.

7. La definición de la religión en têrminos de poder la encontramos en Pratt, J. B., "religion is the serious and social attitude of individuals or communities toward the power or powers which they concieve as having ultimate control over their interests and destinies", en su The Religious Consciousness, Nueva York, 1934. p. 2.

8. Cf. Zubiri, $X$., Inteligencia sentiente. Inteligencia y realidad, op. cir., pp. 196-200; El hombre y Dios, op. cil.. pp. 84-99.

9. Cf. Otıo, R., Das Heilige. über das Irrationale in der Idee des Götllichen und sein Verhälmis zum Rationalen. Breslau, 1917. Sobre esta idea se funda el famoso libro de M. Eliade (Traité d'histoire des religions, París. 1949). Un comentario crítico de esta perspectiva fenomenológica puede verse en Zubiri, X., El problema filosófico de la historia de las religiones. op. cit., pp. 18-28.

10. Cf. Velasco, J. M., "La Tenomenología de la religión en el campo de los saberes sobre el hecho religioso. Sicurus quaestionis", op. cit.. pp. 36-41; Panikkar, R., "Aporfas en la filosofía comparativa de la religión", en Gómez Caffarena, J. y Mardones, J. M.. Cuestiones episiemológicas. Materiales para una filosofía de la religión, vol. 1, op. cir., pp. 85-115.

11. Cf. Zubiri, X., El problema filosófico de la historia de las religiones, op. cit., pp. 85113.

12. Cf. Luckmann. Th., Das Problem der Religion in der Moderne, Freiburg i. B., 1963; lambién su libro sobre La religión invisible, Salamanca. 1973. Una alusión a estos problemas puede verse en Zubiri, X., El hombre y Dios, op. cir., pp. 88-89.

13. Sobre la necesidad de una "re-vivencia" por parte del investigador puede verse Patterson, O. y Äkerberg, H., Interpreting Religious Phenomena, Nueva York, 1981, pp. 86 y ss. Ya R. Olto había hablado de un a priori religioso, que no tendrían todas las personas. Sobre este sensorium especial puede verse también Goldammer, K.. Formenwelt des Religiösen. Stutigart, 1960. p. XXIII. Sobre este punto puede verse Velasco, M.. "La fenomenología de la religión en el campo de los saberes sobre el hecho religioso. Status quaestionis", op. cit., pp. 48-49.

14. Cf. Gadamer, H.-G., Wahrheit und Meshode. Grundzüge einer philosophischen Hermeneurik, Tübingen, 1990 (6" ed.), pp. 165-166, 462-463; tambien en Wahrheit und Meshode. Ergämzungen. Tübingen. 1993 (2"ed.), pp. 62-65.

15. En la filosoffa de Zubiri, el sentido no es objelo de la aprehensión primordial sino del logos, $c f$. Zubiri, X., Inteligencia sentiente. Inteligencia y realidad, op. cir., p. 277. Sin embargo. Zubiri no estudia el logos bajo el concepto general de "sentido", sino que su análisis del mismo le exige una terminología más detallada, cf. Inseligencia y logos, op. cit., pp. 89-107.

16. Cf. Zubiri, X.. El hombre y Dios, op. cis., pp. 89-91. La lista de manifestaciones del poder de lo real está casi literalmente tomada del libro de Eliade. 
17. Cf. Antiseri, D., El problema del lenguaje religioso. Dios en la filosofia analíica. Madrid. 1976; Gómez Caffarena. J. y Mardones, J. (eds.), La Iradición analííca. Materiales para una filosofía de la religión, vol. 2, Madrid, 1992: Velázquez, J. L.. "Las parábolas de Oxford", en Fraijo, M. (ed.), Filosofia de la religión, op. cil., pp. 535-557; Romerales, E., "Philosophical Theology", en ibíd., pp. 558-599.

18. Cf. Zubiri, X., Inteligencia y razón, op. cil. pp. 180-186.

19. Cf. Zubiri, X., Inteligencia y logos, op. cis., p. 263, 272-277. Una crítica al uso de la representación en el neoposilivismo puede verse en Rorly, R., La filosofia y el espejo de la naluraleza, Madrid, 1989, pp. 157 y ss.

20. Sobre el lenguaje en Zubiri puede verse Pintor-Ramos, A., Realidad y verdad. Las bases de la filosofia de Zubiri. Salamanca. 1994, pp. 185-239. Un intento de una conceptuación alternativa puede verse en González. A.. Un solo mundo. La relevancia de Zubiri para la teoría social (Tesis doctoral en la Universidad Ponlificia Comillas), Madrid. 1994, pp. 316-342.

21. Cf. Zubiri, X., El hombre y Dios, op. cit.. pp. 124-125.

22. Cf. Zubiri, X., Sobre el hombre, Madrid, 1986, pp. 15-17.

23. Cf. Wittgenstein, L., Philosophische Unsersuchungen, §§ 23, 30, 40, 47, en su Werkausgabe, vol. I, Frankfurt a. M.. 1984. pp. 250, 254. 26I, 265; Vorlesungen und Gespräche über Ästetik, Psychologie und Religion, Göltingen, 1968, pp. 87-110.

24. Cf. Flew, A., New Essays in Philosophical Theology, Londres, 1966 (5' ed.), p. 46.

25. Cf. Fierro, A., "Comprensión y explicación del hecho religioso", op. cit., pp. 77-79.

26. "Una cosa es verificar en la experiencia el cumplimiento de lo esbozado, y otra muy distinta es verificar que la razón aducida es la única y verdadera razón. (...) Se puede demostrar que la mecánica cuántica no contiene ni admite parámetros ocultos, pero no se puede demostrar que sólo la mecónica cuántica da razón de la física de las partículas elementales". Zubiri, X., Inteligencia y razón, op. cit., p. 273.

27. Sobre la experiencia en Zubiri puede verse Inteligencia y razón, op. cit. pp. $222-$ 257; El hombre y Dios, op. cit., pp. 95-96, 307-317.

28. Cf. Hick. J., Faith and Knowledge. Nueva York, 1957, pp. 150-152.

29. Cf. Pannenberg. W., Grundfragen systematischer Theologie. Gesammelte Aufsäıze, vol. I, Göttingen. 1967, pp. 202-222.

30. Cf. Bonhoeffer, D., Widerstand und Ergebung. Briefe und Aufzeichnungen aus der Haft, München, 1990 (14" ed.). pp. 191-192.

31. Cf. Zubiri, X., El hombre y Dios, op. cil., p. 175. "El mundo y Dios no son dos, pero tampoco son uno. Es una diferencia que está allende el concepto del número y por consiguiente no se puede expresar ni con la cifra dos ni con la cifra uno. La unidad de estas dos dimensiones (no son idénticos, pero tampoco son dos) es lo que expresa un vocablo: justamente la iranscendencia. Dios es transcendente al mundo. Ahora bien, transcendencia no signilica que Dios esté allende el mundo, sino que está en el seno mismo del mundo, pero lundantemente". Zubiri. X., El problema fllosófico de la hisioria de las religiones, op. cit., pp. 145-146.

32. Cf. Hch 17:28.

33. Cf. Barth, K., Kirchliche Dogmatik, Zurich, 1932-1967, vol. 1/1, pp. VIIl-1X, vol. I/ 2. pp. 157, 606-652. Sobre las relaciones de Barth con el catolicismo puede verse Küng. H., Grandes pensadores cristianos. Una pequeña introducción a la teología, Madrid. 1995. pp. 181-207. Una visión conciliadora en H. U. von Balthasar, Karl Barth. Darstellung und Deutung seiner Theologie, Einsiedeln. 1976. 
34. Cf. Jïngel, E.. Goll als Geheimnis der Welt. Zur Begründung der Theologie des Gekreuzigten im Streit zwischèn Theisinus und Atheismus. Tübingen, 1986 (5 ed.).

35. Cf. Zubiri, X.. El hombre y Dios, op. cis., p. 152. Por supueslo, queda en pie la pregunta sobre si "el Dios de las religiones" es el mismo Dios del cristianismo. Desde una perspecliva proteslante. E. Brunner ha acometido una critica semejante a los conceptos griegos que predeterminan conceptos teológicos, of. Brunner, E., Wahrheit als Begegnung, Zürich, 1963 (2' ed.). También Zubiri, como Brunner, ha analizado la verad como encuentro, $c f$. Inseligencia y razón, op. cis., pp. 258-263, 292-297.

36. Cf. Barth, K., "La humanidad de Dios". en sus Etsayos ıeológicos. Barcelona. 1977. pp. 9-34.

37. Cf. Przywara, E., Analogia Ėstis, en sus Schriften, vol. 3, 1962, p. 334. Se trata de la expresión utilizada por el cuarto Concilio Lateranense (DS 806).

38. Cf. Jüngel, E., Gort als Geheimnis der Welt, op. cis., pp. 383-408.

39. Cf. Zubiri, X., El hombre y Dios, op. cit., p. 172.

40. Esta es precisamente la crítica que le ditige Moltmann, J., Trinität und Reich Gottes. Zur Gorteslehre, München. 1980 (2 ed.), pp. 154-161.

41. Cf. Zubiri, X., Sobre el sentimiento y la volición, Madrid. 1992, pp. 201-256.

42. Precisamente por ello, Jüngel no piensa la pobreza como realidad, sino como condición existencial de amenaza del ser humano por la nada, $c f$. Goll als Geheimnis der Welt, op. cil., pp. 280-283.

43. Zubiri, X., El hombre y Dios, op. cit., p. 380. 